\title{
Supervision of Offenders with Intellectual Disabilities by the Probation Service: Challenges and Problems
}

\section{Mike Hellenbach*}

Coventry University, Germany

*Corresponding author: Mike Hellenbach, Coventry University, Germany, Tel: 004417642656462; E-mail: m.hellenbach@hotmail.com

Received date: February 22, 2017; Accepted date: February 27, 2017; Published date: February 28, 2017

Copyright: (c) 2017 Hellenbach M. This is an open-access article distributed under the terms of the Creative Commons Attribution License, which permits unrestricted use, distribution, and reproduction in any medium, provided the original author and source are credited.

\begin{abstract}
Background: Limited available evidence suggests that offenders with intellectual disabilities (ID) constitute a significant minority among probationers. Yet, little is known about how probation officers negotiate competing structural demands when supervising and managing this population. The author seeks to address this gap by focussing on the assessment proceedings by which probationers are evaluated in their criminogenic needs. It is envisaged that this will help to shed light on the decision-making by probation officers when engaging with probationers with ID.
\end{abstract}

Method: This paper is based on qualitative methods. In total six semi-structured, in-depth interviews were conducted with probation officers from the English North-West region. The data were analysed using the modified Grounded Theory approach.

Findings: Three main themes emerged during the course of the analyses; revolving around the identification of probationers with ID, how ID is contextualised by probation officers during risk assessment activities, and role of ID in determining the outcomes of supervision.

The data of this paper suggest that the proceedings used by the probation service to risk-assess and supervise offenders in the community promote positivist thought around culpability, intent and guilt. As a consequence, offenders with ID are at risk of being inaccurately assessed in their needs by the probation service, which increases the likelihood of this population being incorrectly managed and supervised. In conclusion, the assessment tools utilized by the probation service appear to favour measures of control and discipline over self-advocacy, thereby significantly increasing the risk for offenders with ID to be drawn into and processed through the criminal justice system.

Keywords: Intellectual disability; Criminal justice; Probation; Vulnerable offender; Community sentence

\section{Introduction}

Over the last 20 years, people with intellectual disabilities (ID) who offend have received increasing attention by politicians and decision makers and extensive efforts have been made to better accommodate the needs of this population when engaging with the criminal justice system. An ID is characterised by significant impairments in cognitive and social intelligence. The World Health Organisation (WHO) defines ID as: 'A condition of arrested or incomplete development of the mind, which is especially characterized by impairment of skills manifested during the developmental period, skills which contribute to the overall level of intelligence, i.e. cognitive, language, motor, and social abilities' [1].

Because of these impairments, it has been recommended that people with ID should be either diverted from prosecution or if taken to court, community orders should be favoured over prison sentences. In previous research, however, it has been suggested that a growing number of people with ID are dealt with through the criminal justice system [2]. In the Criminal Justice Joint Inspection report [3], which reflects the findings of $\mathrm{HM}$ Inspectorate of Probation, HM
Inspectorate of Constabulary, HM Crown Prosecution Service Inspectorate and the Care Quality Commission, the proportion of people with ID who have contact with criminal justice agencies was assumed to be up to $30 \%$, although no accurate estimate of the size of this population could be made due to failures in recording and identifying this issue at different stages of the criminal justice system [3].

Equally, there is ample evidence of this population being overrepresented at police stations and in prisons [4,5]. Although estimates of prevalence differ across studies, depending on definition of ID and screening measures used, international data suggest that $7 \%-10 \%$ of convicted offenders within the prison system have an Intelligence Quotient (IQ) in the mild ID range (IQ50-69) and a further 20\% have a borderline ID (IQ70-80) [6-10].

Whilst prevalence of ID among prisoners has been receiving moderate attention in research, far less is known about offenders with ID who have been sentenced to a community order under the supervision by the probation service. In one of the few studies focusing on this area, Mason and Murphy [11] reported that about 19\% of their sample of probationers did score positive for mild or borderline ID, suggesting a significant minority of people with ID among offenders who are supervised by the probation service. In the same study, the authors highlighted a range of special support needs that this 
population presented, such as difficulties in keeping appointments and following probation rules [11].

People with ID can present with conduct disorders, impaired communication, mental illnesses, physical health conditions or reading and writing difficulties [12-18], which in combination can significantly impact on their ability to comply with conditions of their community order. The high level of need that offenders with ID are likely to have whilst serving a community sentence can make their supervision more challenging and work-intensive $[19,20]$.

The probation service, however, demonstrates like no other agency how the criminal justice system has changed in its focus, having become more punitive and rigorous in the way it operates [21-23]. Increasing efforts have been undertaken by succeeding governments to unify the standards used by probation trusts to assess and manage offenders [24]. In previous research, it was reported that the change in political rhetoric, stressing discipline, control and punishment, has resulted in an emphasis on meeting organisational targets, significantly restricting probation officers in their flexibility and creativity when supervising offenders in the community $[25,26]$.

In order to assess probationers in their needs and risks, probation officers use the Offender Assessment System (OASys). Offenders are scored in their dangerousness, risk of harm and risk of reoffending in relation to their responses to questions determined by OASys. The tool consists of static measures, such as age or gender, and dynamic factors, for example family status or drug addictions. OASys has been extensively criticised in previous research for undermining probation officers in their independent professional risk assessments of offenders [27-32].

It is important to recognise that since it was introduced in 2002, OASys has undergone continuous changes to allow for better identification and facilitation of offenders with special needs. In this context, awareness of offenders with ID has been increasing. For example, cognitive intelligence is somewhat considered as part of the needs requirements section in OASys, which prompts probation officers to test offenders in their ability to recognise problems, problem solving skills, awareness of consequences, understanding of other people's views and concrete and abstract thinking. Furthermore, in a recent mission statement by the National Offender Management Service (NOMS) the need for early and accurate identification of offenders with ID was emphasised, allowing for reasonable adjustments to services and programmes to meet the needs of this population [33].

However, most programmes for offenders with ID appear to predominantly focus on sex offending [34], such as the Adapted Sex Offender Treatment Programme-Community Version, or are only available in prisons [35]. Moreover, it is particularly concerning that the probation service still seems to fail to assure the suitability of programmes for offenders with special needs [3].

Little is known about the supervision of specific vulnerable groups by probation officers. It is surprising that regardless of Mason and Murphy's [11,20] study, which indicated people with ID to be constituting a significant minority among probationers, no further research in this area has been conducted since. In this article, the author will try to address this gap by investigating proceedings by which offenders are assessed by the probation service to gain an insight into how probation officers negotiate criminal justice targets when engaging with probationers with ID. In particular, attention will be paid to how OASys informs and shapes the decision-making of probation officers. It is envisaged that this approach will allow for a critical evaluation of OASys as an assessment tool for offenders with ID as well as improving our understanding of how offenders with ID, who have been sentenced to a community order, are supervised by the probation service.

\section{Methods}

This study draws on qualitative data that were generated in 2011 as part of a study, investigating processes by which people with ID engage with the criminal justice system. In this context, 35 interviews were conducted with a range of criminal justice agents, such as probation officers, police custody sergeants, crown prosecutors, health professionals, judges and magistrates. The study produced knowledge about processes by which the criminal justice system maintains its traditional normative and enforcement powers when engaging with vulnerable defendants.

Within the context of the present study, a definition of ID was purposefully adopted concentrating on impairments in social functioning as outlined in the UK Government's Valuing People White Paper, whereby a person with ID has:

- A significantly reduced ability to comprehend and process new or complex information.

- Impairments in their social functioning, particularly in relation to getting by independently.

- The impairments in intellectual functioning have to be present before adulthood, with a lasting effect on development.

By concentrating on social interactions between people with ID and their physical and social environment, the definition of ID in this study was explicitly social and less medical in nature. The definition supported analysing the concept of vulnerability in relation to social constructions of crime, punishment, intent, culpability and guilt, to gain an understanding of how the interplay of these concepts created a discursive framework within which criminal justice professionals interacted with people who have ID. As part of the information material with which interviewees were provided prior to each interview, a detailed explanation of ID was given outlining the definition of ID used in this study.

In total, six probation officers from two different probation trusts in the English North West region responded to the research invitation and agreed to take part in this study. All interviewees had many years of experience as probation officers.

In all interviews, three broad areas were addressed:

- the process by which an individual's capacity of understanding was established

- experience of supervising suspected offenders with learning disabilities

- preparation and training for interviewing and dealing with probationers who have ID

It was decided to use semi-structured interviews to maximise opportunities for respondents to make comprehensive statements and give explanations at their own pace. It was envisaged that this approach would help revealing the importance and significance of topics, concerns, and meanings as perceived by respondents [36,37]. All interviews were conducted with probation officers face-to-face in their offices and took between 1.5 and 2 hours. 
Page 3 of 7

The data were analysed using a modified Grounded Theory [38] approach. It turned out to be impossible to conduct a theoretical sample as suggested by Glaser and Strauss [38]. Instead, respondents were purposefully recruited in relation to specific characteristics. For the purpose of this study, respondents had to be probation officers who were located in the English North West region. Research invitation letters were posted to three different probation trusts, containing detailed information about the research purpose as well as contact details of the researcher, allowing potential respondents to make contact for organising an interview. Written consent was obtained from all respondents immediately before an interview was conducted. The study received approval by the NHS Research Ethics Committee.

Three main themes emerged during the course of the analyses:

- Assessment of ID

- Intellectual functioning vs. employability

- The reformable offender

\section{Findings}

\section{Assessment of ID}

During the interviews with probation officers it became apparent that there was no formal process allowing for a probationer's intellectual capacity to be assessed.

If somebody has got mental health issues we will often know that before they get to us. If somebody has got mental health issues there is somebody I can go to immediately to get that confirmed. If somebody has got learning needs there isn't a process, that doesn't get flagged up. There is no system for that there is no assessment for that.

\section{(Probation Officer 5)}

Furthermore, it was highlighted that probation officers had not received training on issues around ID, which indicated that probationers with ID either had to be already known as being impaired in their cognitive functioning or had to display obvious signs of their needs:

Interviewer (IR): Let me just clarify one thing. In case there is somebody coming here and there is no information in place that this person may have an ID, then it is quite unlikely that it will actually come up?

Interviewee (IE): I would say that depends on what was written previously, when there has been a previous assessment.

IR: Yeah, but that's what I mean, if there is no previous assessment...

IE: If there is no previous assessment then I would have to depend on my own sort of nose. But I don't recall any training on spotting people with learning difficulties (This particular respondent interchangeably used the terms learning difficulties and learning disabilities. At the beginning of the interview the difference between difficulties and disabilities was explained to the interviewee. The respondent, however, continued to interchangeably use both terms. It was, nevertheless, established throughout the interview that the interviewee was, indeed, referring to learning/ID and not learning difficulty.) which I think is a deficit.

\section{(Probation Officer 4)}

Some of the interviewees stressed that identifying an ID, especially at pre-sentencing stage, was complicated further as the majority of probationers exhibit educational needs, deficits in their social competence or difficulties in understanding and communicating.

I suppose when you see most young people who come through our system you are going to get a fairly high proportion who haven't made it through the educational system.

\section{(Probation Officer 2)}

You can't assume we would pick that [ID] up necessarily at that stage [pre-sentence report] because we work with lots of people for whom communication or the spoken word isn't, you know, is difficult to understand.

\section{(Probation Officer 6)}

\section{Intellectual functioning vs. employability}

When trying to identify the needs of probationers, OASys is the only assessment tool available to probation officers. It transpired, however, that in OASys intellectual capacity is equivalent to employability. In other words, in OASys a person's ID is only considered in relation to basic skills, necessary to gain employment.

IR: Is there actually anything that allows you to measure an individual's intellectual capacity?

IE: As far as I am aware, people come and we do a form, a basic skills assessment. Again, they tick boxes at what age they left school, if they have any qualifications, have they worked. If they are coming out at a certain score then we will put them on a basic skills assessment.

\section{(Probation Officer 2)}

This approach reflects how risks and needs of criminal offenders are measured in OASys in relation to key competencies and abilities that are necessary to gain employment. An offender's risk of reoffending, in this context, is perceived to be the result of an individual's lack of competencies excluding them from the labour market.

\section{IR: How are probationers assessed in their intellectual functioning?}

IE: There are the two sections: education and training and employment section. In the education, training and employment sections we are looking at things like, did they go to school? Did they have any complications? Have they had employment? Have they had good continuous employment? Are they motivated in doing any more training? Are they interested in training? That sort of thing. We assess if the person has poor essential or basic skills.

\section{(Probation Officer 5)}

Consequently, in OASys assumed causes of criminal behaviour that are rooted in an offender's deficits are translated into seemingly objective risk factors that can be ranked in their severity. Hence, the approach taken by the probation service does not allow considering an offender's reasoning in a particular situation but, instead, reduces attention to the situation itself. This can have devastating consequences for offenders with ID as their risk assessment, and thus their management plan generated by OASys, can be incorrect and might not properly reflect their needs and abilities. Such a scenario was described by one of the respondents:

He got a community order with the requirement to complete our "Think first" programme which, as the name suggests, is a cognitive behavioural programme. It's of 22 sessions in duration, each session $2 \frac{1}{2}$ hours long, it's group work based, it's all reading and writing. How on 
earth an individual suffering from ADHD is supposed to get through that is beyond me.

\section{(Probation Officer 1)}

In this context, the introduction of OASys has not only had a great impact on the way probation staff carry out assessments of probationers. The tool has also changed the focus and professional ethos of probation officers. Lancaster and Lumb [30], for instance, argue that OASys limits assessments to the risks an offender might pose to society, but does not allow an assessment of the rights to which a person should be entitled whilst being supervised. Consequently, the needs of an offender have been replaced by issues around public protection and less attention is paid to critically analysing causes of risks and how to reduce them $[28,30]$. It is, for example, not part of the OASys system to inquire whether the probationer is able to internalise some of the values that are supposed to be conveyed through probation supervision:

We will help them to gain qualifications and employment skills. So we do that kind of stuff. So we cover that side of things. But I think when it gets into the question of can they understand the work that we are doing, when you have to adapt in the way that you work with them, that is where I think the problems come in.

\section{(Probation Officer 3)}

Instead, offenders are allocated to groups in accordance with their criminogenic needs and their risk of harm as measured by OASys [39]. This evokes a conflict within the work of probation officers since the success of a person's probation period is measured in relation to their understanding of their wrongdoing.

\section{The reformable offender}

When evaluating a probationer's progress, respondents particularly focussed on an offender's willingness to cooperate with their supervising probation officer. The successful implementation of a probation order, which informs the continuous risk assessment around an offender's propensity to reoffend, was based on a close collaboration between offender and probation officer.

It (an offender's cooperation) is a medium towards, to test the amount of remorse regarding the offence, explore attitudes to victims and sort of see whether or not there is a high or medium risk or no risk of reoffending.

\section{(Probation Officer 4)}

When becoming suspicious about a probationer's level of communicating and understanding, the supervising probation officer has to make a decision as to whether needs are caused by a lack of education or if a person has, indeed, an ID:

I was just talking to someone thinking, you know, you have got really poor comprehension. You seem to not be able to grasp at all what we are discussing. There is immaturity and then there is learning needs and sometimes you have to try and find out which one of the two it is.

\section{(Probation Officer 5)}

The probation officer quoted above assessed an individual's intellectual capacities with regards to a person's ability to distinguish between right and wrong. Therefore, probation officers are reevaluating the legal condition of men's era during sanctioning, which allows embedding a potential breach of a probation order into an epistemological framework of free choice.
As the quote below exemplifies, a concept of free choice was used when offenders were evaluated in their progress whilst serving a community sentence. The concept of free choice was based on a rational actor having capacity to fully comprehend the complexity of their acting, and also understanding how criminal justice professionals may interpret this acting in relation to central aspects of rehabilitation.

I fully admit I am not trained in assessing learning disabilities. But I felt that he had a sufficient insight to know that what he had done was wrong. However, despite the fact knowing that it was wrong he chose not to sort of say that's the way life is, you know. There was very little remorse, to sort of, no, you are right, I shouldn't have done it. He actually tried to deny it and he wanted to go back to court and change his plea to not guilty.

\section{[...]}

Now, had he been more cooperative I would have probably got some, an assessment done as to sort of his learning skills because that was a condition of his order as well, to improve his skills at sort of reading and writing etc. [...] In the end, he has only recently appeared in court for this sort of assault and the court made the judgement that, you know, it was a pretty serious assault and he got five months' prison for it and his order was revoked. So I have got no opportunity, well I, I wanted to work with him, but I couldn't do any work with him because he just wouldn't cooperate.

\section{(Probation Officer 4)}

As the above quote demonstrates, acknowledging past offending behaviour and displaying remorse were key variables by which progress and success of probation supervision were measured by interviewees. By using a model of free choice within their supervision of offenders, respondents seemed to be more likely to interpret obstructive behaviour in terms of uncooperativeness rather than impaired intellectual functioning.

Consequently, probationers who had not been clearly identified as intellectually disabled and did obstruct the probationary managerial process were more likely to be perceived as uncooperative. At presentence stage this might entail for a person to be assessed as unsuitable for a community order by their supervising probation officer, increasing the likelihood for the probationer in question to be sentenced to imprisonment:

So, in many cases if it appears to us that there is basically nothing we can do and there is a criminogenic need to address but unfortunately the offender is giving absolutely no indication of any cooperation, is resistant to the process from the start, I personally would not be recommending or proposing, I should say, a community based sentence.

\section{(Probation Officer 4)}

\section{Discussion}

In the past, increased efforts by politicians and decision makers have been undertaken to divert people away from the criminal justice system or where this is not possible to favour community treatment over imprisonment. If management of offenders with ID in the community is to be meaningful and successful, probationary supervision has to be based on an accurate understanding of ID to allow for correct assessments and the generation of management plans that are suitable for this population. 
This study, however, has confirmed previous findings [32] whereby OASys channels attention to processing offenders and completing assessments whilst limiting probation officers in their analysis of an offender's narration. Within the probation service this has led to a greater emphasis on an offender's engagement with their supervising probation officer rather than their capacity to reason. As a consequence, intellectual capacity appears to be constructed by probation officers in terms of impaired employability rather than in terms of an impaired understanding. This explains why people with ID are often perceived as difficult to be processed and not as a group with special needs requiring individual support as stated in the Criminal Justice Joint Inspection report [4].

As this study has shown, this erroneous perception of ID increases the likelihood for probationers with ID to be inaccurately assessed in their needs, exposing this population to a greater risk of failing their community sentence or excluding them from probation altogether. In this context, the individualising OASys assessment, which is based on a concept of a reasonable and rational actor, leaves ultimate responsibility for failing to comply with a court order with those on probation and, therefore, creates a discourse that is both self-justifying and self-perpetuating.

Most of the probation programmes and activities, especially those around education and skill training, require probationers to have capacity to understand and process complex information. It has been stressed in the literature that many of the probation programmes require attendees to have an IQ of 80 or higher $[3,40]$. In the recently published report by the Foundation for People with Learning Disabilities (FP) it was stated that accredited programmes developed by NOMS, which are aimed at the reduction of risk of re-offending and that are available across the prison and probation service, still fail to cater for people with an IQ below 80 [41]. In this context, it is surprising that OASys does still not include an assessment of an offender's level of intellectual functioning, increasing the risk of people with ID to remain unidentified in their special needs when engaging with the probation service.

The findings of this study suggest that it is advisable for OASys to be amended to better recognise and facilitate the needs of offenders with ID. Future versions of the tool should incorporate an evidence-based assessment of intellectual functioning, allowing probation officers to better consider the needs of probationers with ID when preparing presentence reports, writing management plans or supervising this group in the community.

During the analysis of the interviews it became apparent that the probation service seemed to be ill equipped for dealing with offenders with ID. The data of this study indicates that probation officers had no accurate knowledge of what characterises a person with ID, or how supervision should be adjusted to the needs of probationers with ID. The findings of the aforementioned Criminal Justice Joint Inspection indicate that this problem has remained unaddressed. Therefore, specialist training for probation officers might be beneficial, aiming at increasing knowledge of problems that probationers with ID can face when serving a community sentence. In this context, it would be especially useful to establish better cooperation between probation services and organisations specialised in working with people with ID, such as Mancap. Such collaboration could help overcoming probation officers' feeling of helplessness when dealing with offenders with ID, which was often voiced by respondents in this study.
However, better training will only partially improve the supervision of offenders with ID in the community. As recognised by NOMS, working with people who are impaired in their intellectual functioning requires an individualised approach that equally takes account of abilities and needs of every individual person [42]. Taking such an approach, however, will not only be contrary to the prescriptive nature and the positivist focuses of the OASys assessment, but is also likely to take up more resources.

In this context, it is very concerning that there has been increasing pressure on the probation service, resulting from budget cuts and a high number of cases. With the introduction of new court orders, the total annual probation caseload increased by $39 \%$ between 2000 and 2009 to 243,434 whilst the number of probation officers decreased in the same time period by about 17\% [24]. Although, since 2009 the caseload has decreased every year and has fallen to 224.283 at the end of 2012, the number of probation officers has also further decreased by more than $10 \%$ between 2010 and 2013 [34].

Bureaucratic tasks coupled with a high caseload have resulted in probation officers spending only $25 \%$ of their time on seeing offenders in one-to-one meetings [43]. These developments are likely to hinder a successful implementation of guidelines published by [42], whereby probation officers should take a more individualised approach when engaging with offenders with ID in one-to-one consultations to reduce risk of serious harm.

Failing the ID population while serving a community sentence does not only undermine attempts to empower people with disabilities but will also come at high social and financial costs. If breeching their probation order, offenders with ID are likely to receive a prison sentence. If imprisoned, however, people with ID have been shown to be four times more likely to re-offend after their release than their nondisabled counterparts [44], and are twice as likely to attempt suicide or to engage in self-harming behaviour during their imprisonment [45].

Findings of the Criminal Justice Joint Inspection report suggest that five years after Lord Bradley's report on people with ID and mental health problems in the criminal justice system, vital recommendations have not been implemented [3]. Early identification and adequate management of offenders with ID still appear to be major problems within criminal justice proceedings. The absence of appropriate services, the lack of knowledge and training, failures in passing on information, the lack of easy read information and instructions often result in unfair treatment of offenders with ID who engage with criminal justice agencies [46], which can lead to a situation where as Jenny Talbot put it, people with an ID are discriminated against on grounds of their disability.

This article is based on interviews that were conducted in 2011. However, the abovementioned recently published research findings relating to processes by which offenders with ID engage with the criminal justice system as well as the latest literature on probation services indicate that demands and pressures resulting from the structural setting in which individual actors within the probation service negotiate their decisions and actions have remained unaltered. Therefore, the empirical data quoted in this article still provide a valuable insight into micro-level interactions during probationary supervision of offenders with ID.

The small number of respondents as well as having only considered the accounts of members of the probation service constitutes a limitation of this study. Therefore, findings of this study should be interpreted with care. In future research, probationers with ID need to 
be more actively involved as respondents to allow for their voices to be heard. In general, the lack of research in relation to probationers with ID is alarming. In order to get a clearer understanding of service needs, an accurate estimate of prevalence of this population at the various stages of the criminal justice system is urgently needed.

Efforts that have been undertaken by politicians and decision makers over the last 20 years are encouraging and significant improvements have undoubtedly been achieved to better recognise people with ID in their needs within the general public as well as within the criminal justice system. A promising recent development, for example, is the announcement made by Care and Support Minister, Norman Lamb in 2014 to invest $£ 25$ million for liaison and diversion services at police services and courts across the country. One of the 10 benefiting constabularies will be Merseyside, where previous research has demonstrated the provision of ID services at police stations to be inadequate [47]. A first evaluation of these services is expected by 2017 and if successful the programme will be extended to the rest of the country. However, criminal justice principles of fairness and justice will remain impaired as long as recommendations of previous policy and research reports are not implemented more thoroughly and with more consistency.

\section{Conclusion}

The proceedings used by the probation service to risk-assess and supervise offenders in the community promote positivist thought around culpability, intent and guilt. In relation to people with ID, this approach appears to significantly increase the risk for this population to be drawn into and processed through the criminal justice system. Offenders with ID can often require an intense and time-consuming supervision which currently appears unlikely to be provided by the probation service considering the tools used to assess probationers as well as structural pressures within which probation officers have to organise their work.

\section{References}

1. http://apps.who.int/classifications/icd10/browse/2015/en\#/V

2. Taylor JL, Lindsay WR (2010) Understanding and treating offenders with learning disabilities: A review of recent developments. J Learn Disabil Offending Behav 1: 5-13.

3. Department of Health (2014) A joint inspection of the treatment of offenders with learning disabilities within the criminal justice system Phase 1 from arrest to sentence. A Joint Inspection by HMI Probation, HMI Constabulary, HM Crown Prosecution, Inspectorate and the Care Quality Commission.

4. Cockram J (2005) Justice or differential treatment? Sentencing of offenders with an ID. J Intellect Dev Disabil 30: 3-13.

5. Talbot J (2008) Prisoners' voices: Experiences of the Criminal Justice System by Prisoners with Learning Disabilities and Difficulties. London: Prison Reform Trust.

6. Dias S, Ware RS, Kinner SA, Lennox NG (2013) Physical health outcomes in prisoners with intellectual disability: a cross-sectional study. J Intellect Disabil Res 57: 1191-1196.

7. Gunn J, Maden A, Swinton M (1991) Treatment needs of prisoners with psychiatric disorders. BMJ 303: 338-341.

8. Susan H, Shackell P, Mottram P and Lancaster R (2007) The prevalence of ID in a major UK prison. Br J Learn Disabil 35: 162-167.

9. Herrington V (2009) Assessing the prevalence of intellectual disability among young male prisoners. J Intellect Disabil Res 53: 397-410.
10. Søndenaa E, Rasmussen K, Palmstierna T, Nøttestad J (2008) The prevalence and nature of intellectual disability in Norwegian prisons. J Intellect Disabil Res 52: 1129-1137.

11. Mason J, Murphy G (2002) Intellectual disability amongst people on probation: prevalence and outcome. J Intellect Disabil Res 46: 230-238.

12. Cooper SA, Smiley E, Morrison J, Williamson A, Allan L (2007) Mental ill-health in adults with ID: prevalence and associated factors. Br J Psychiatry 190: 27-35.

13. Cooper SA, Smiley E, Jackson A, Finlayson J, Allan L, et al. (2009) Adults with ID: prevalence, incidence and remission of aggressive behaviour and related factors. J Intellect Disabil Res 53: 217-232.

14. Einat T, Einat A (2008) Learning disabilities and delinquency: A study of Israeli prison inmates Int J Offender Ther Comp Criminol 52: 416-434.

15. Emerson E (2011) Health inequalities and people with learning disabilities in the UK. Learning Disability Review 16: 42-48.

16. Kwok H, Cheung PW (2007) Co-morbidity of psychiatric disorder and medical illness in people with intellectual disabilities. Curr Opin Psychiatry 20: 443-449.

17. Lindsay W, Carson D, Holland A, Taylor J, O'Brien G, et al. (2013) The impact of known criminogenic factors on offenders with ID: Previous findings and new results on ADHD. J Appl Res Intellect Disabil 26: 71-80.

18. Lowe K, Allen D, Jones E, Brophy S, Moore K, et al. (2007) Challenging behaviours: prevalence and topographies. J Intellect Disabil Res 51: 625-636.

19. Mason J (1999) Responding to people with learning disabilities in the probation service. Br J Forensic Pract1: 16-21.

20. Mason J, Murphy G (2002b) People with ID on probation: An initial study. J Community Appl Soc Psychol 12: 44-55.

21. Kendall K (2004) Dangerous thinking: A critical history of correctional cognitive behaviouralism. In: G. Mair (eds.) What matters in Probation. Cullompton, (UK): Willan Publishing, pp: 53-89.

22. Mair G, Burke L (2012) Redemption, Rehabilitation and Risk Management: A History of Probation. Abingdon, Routledge.

23. Robinson G, Crow I (2009) Offender Rehabilitation: Theory, Research and Practice. London, Sage.

24. Ledger J (2010) Will probation pay the price? Probation Journal 57: 415-422.

25. Lawrie C (2011) What Happened to Probation between 1997 and 2010? A Probation Professional's Perspective. In: Silvestri A (Eds.) Lessons for the Coalition: An End of Term Report on New Labour and Criminal Justice. London: Centre for Crime and Justice Studies, pp: 53-57.

26. Worrall A, Mawby RC (2013) Probation worker responses to turbulent conditions: Constructing identity in a tainted occupation. Aust $\mathrm{N} \mathrm{Z} \mathrm{J}$ Criminol 46: 101-118.

27. Clarke J, Newman J (1997) The Managerial State. London (UK): Sage.

28. Crawford A (2007) What impacts on quality assessment using OASys? Probation Journal 54: 157-170.

29. Fitzgibbon WD (2008) Fit for purpose? OASys assessments and parole decisions. Probation Journal 55: 55-69.

30. Lancaster E, Lumb G (2006) The assessment of risk in the National Probation Service of England and Wales. J Soc Work 6: 275-291.

31. Mair G, Burke L, Taylor S (2006) The worst tax form you've ever seen? Probation Officers' views about OASys. Probation Journal 53: 7-23.

32. Mehta A (2008) Fit for purpose: OASys assessments and parole decisions - A practitioner's view. Probation Journal 55: 189-194.

33. Ministry of Justice (2012) NOMS Commissioning Intentions for 2013-2014.

34. Ministry of Justice (2013) Probation Service workforce quarterly reports 2012/2013.

35. Oakes PM (2013) Adapted Thinking Skills Programme. Evaluation Report for National Management Service. Hull (UK): Foundation for People with Learning Disabilities. London, UK. 
Citation: Hellenbach M (2017) Supervision of Offenders with Intellectual Disabilities by the Probation Service: Challenges and Problems. J Foren

36. Neal S (1995) Researching powerful people from a feminist and antiracist perspective: A note on gender, collusion and marginality. Br Educ Res J 21: 517-531.

37. Rubin HJ, Rubin S (2005) Qualitative Interviewing: The Art of Hearing Data. London: Sage.

38. Glaser BG, Strauss AL (1967) The Discovery of Grounded Theory. Chicago IL: Adline.

39. Bullock K (2011) The construction and interpretation of risk management technologies in contemporary probation practice. Br J Criminol 51: 120-135.

40. Canton R, Hancock D (2007) Dictionary of Probation and Offender Management. Cullompton (UK): Willan.

41. Foundation for People with Learning Disabilities (2014) Adapted Thinking Skills Programme Evaluation Report for National Offender Management Service.

42. National Offender Management Service (NOMS) (2012) Sentence Planning. PSI 41/2012.
43. House of Commons Justice Committee (2011) The Role of the Probation Service.

44. Hutchison M, Hummer D, Wooditch A (2013) A survey of existing programme strategies for offenders with intellectual and developmental disabilities under correctional supervision in Pennsylvania. Probation Journal 60: 56-72.

45. Hassiotis A, Gazizova D, Akinlonu L, Bebbington P, Meltzer H, et al. (2011) Psychiatric morbidity in prisoners with intellectual disabilities: analysis of prison survey data for England and Wales. Br J Psychiatry 199: 156-157.

46. Parish C (2014) Clients in the criminal justice system cannot access services. Learn Disabil Pract 17: 8-9.

47. Hellenbach M (2012) Intellectual disabilities and criminal justice: Custody sergeants' perceptions of alleged offenders with intellectual disabilities. Br J Learn Disabil 40: 15-22. 